\title{
Molecular Identification of Pm4 Powdery Mildew Resistant Gene in Oat
}

\author{
Sylwia OKOŃ*, Tomasz OCIEPA, Aleksandra NUCIA \\ University of Life Sciences in Lublin, Institute of Plant Genetics, Breeding and Biotechnology, Akademicka 15, 20-950 Lublin, \\ Poland:sylwia.okon82@gmail.com ("correspondingauthor);tomasz.ociepa@up.lublin.pl;aleksandra.nucia@up.lublin.pl
}

\begin{abstract}
The selection of specific plants with desirable traits supported by molecular markers is one of the most important tools in modern breeding programs, which lead to reduce time and cost of selection. The aim of presented study was identification of dominant markers associated with $P m 4$ powdery mildew resistant gene in oat. To identify dominant silicoDArT markers for $P m 4$ gene, $F_{2}$ mapping population 'Av1860' $\times$ 'Fuchs' were analyzed using DArTseq methodology. Among obtained 46230 silicoDArT markers, 126 markers were high correlated with resistance to powdery mildew in oat conditioned by $\mathrm{Pm} 4$ gene. Among selected markers, 48 sequences have been chosen for potential conversion into specific STS markers. Finally, only 20 were suitable for primer design. As a result, 5 converted markers amplified expected products in resistant bulks, 3 of them segregated according to resistance in the whole population and shoved high correlation coefficient between marker and phenotype observation. Converted markers based on PCR could be used for identification of Pm4 gene in oat. Obtained results confirm the possibility of converting silicoDArT markers into PCR-based technique, which can be used in marker assisted selection (MAS).
\end{abstract}

Keywords: Avena sativa; Blumeria graminis; molecular markers; resistance

\section{Introduction}

Powdery mildew caused by Blumeria graminis DC. f.sp. avenae Em. Marchal. is one of the most important foliar disease of cultivated oat is. This worldwide disease appears every year and causes big crop loses (Lawes and Hayes, 1965; Jones, 1977; Schwarzbach and Smith, 1988; Sebesta et al., 1991; Clifford, 1995; Aung et al., 1977; Roderick et al., 2000). Large genetic changeability and ability to generate new forms by mutations and DNA recombinations makes this pathogen easily adaptable to new conditions (Bennet, 1984; Bayles, 1997). The use of fungicides is the easiest method of protection against pathogen attack, but cultivated oat is a low-input crop which grown on less productive lands, so in this case, breeding resistant cultivars seems to be more economical and more environmental friendly method for controlling and limitation occurrence of oat powdery mildew. Till date, 8 resistant genes against powdery mildew have been described in oat. Hsam et al. (1997, 1998), Okoń (2012), Okoń et al. (2016) demonstrate that only 3 of them (Pm1,Pm3 and Pm6) were used in worldwide breeding programmes. However resistant to powdery mildew controlled by these genes is breaking down by the existing races of powdery mildew (Okoń, 2015). Nowadays the most effective sources against powdery mildew in oat is Pm4 resistant gene (Okoń, 2015).
Pm4 was derived from the diploid oat species A. barbata accession Cc4897 (Rajhathy, 1963; Aung and Thomas, 1978). Resistance controlled by this gene was identify in a field nursery in 1978 (Jones and Jones, 1979), also Pm4 gene has remained effective at all EODN (European Oat Disease Nursery) nurseries outside Britain (Sebesta et al., 1997). Okon (2015) confirm that resistance conditioned by Pm4 gene is still effective in central Europe. High level of resistance continuing in recent years suggested that Pm4 should be used in breeding programmes to increase level of resistance to powdery mildew in cultivated oat.

The fundamental basis of plant breeding is the selection of specific plants with desirable traits. Marker-assisted selection (MAS) is one of the most important tools in modern breeding programs, which lead to reduce time and cost of selection. This method based on identification of molecular markers associated with particular traits, and combines the knowledge about a genotype and phenotype of the analyzed plants. MAS increased the efficiency of conventional selection methods and offer the possibility to identify genotypes with desired traits in seedling stage and irrespective of environmental conditions (Collard et al., 2005; 2008). This advantage of MAS is very important in selection of genotypes resistant to fungal diseases. Using molecular markers instead of physiological tests lowers the cost and time of selection (Wight et al., 2005; Yu and Herrmann, 2006; Chhetri et al., 2017). 
The presented work is the first report about the effort of the development of an effective method for the identification of the powdery mildew resistance gene Pm4 in oat. The aim of presented study was identification of dominant DArTseq markers associated with $P m 4$ resistant gene and conversion of these markers into simple PCRbased method.

\section{Materials and Methods}

\section{Plantmaterial}

The subject of the study was segregating population derived from cross between line 'Av1860' possessing Pm4 powdery mildew resistant gene with susceptible oat cultivar 'Fuchs'. 157 individuals of $F_{2}$ population were phenotyped based on host-pathogen test. After tests all individuals were planted on experimental plot. $F_{3}$ generation seeds were collect from every $\mathrm{F}_{2}$ individuals and tested using hostpathogen methodology. Obtained observations allows select both homozygous-resistant and homozygous-susceptible individuals for molecular analysis.

\section{Resistance tests}

Resistance of the individuals in $F_{2}$ and $F_{3}$ populations was estimated based on 2 single spore powdery mildew izolates avirulent to Pm4 gene. Selected izolates were collected from different parts of Poland. Single spore izolates were obtained according to description in our previous publication (Okoń and Kowalczyk, 2012a). Hostpathogen tests were carried out on the first leaves of 10-dayold seedlings according to method described by Okon and Kowalczyk (2012a). The effect on the leaves was determined ten days after inoculation. Reactions to the isolates were grouped into two classes: resistant, from 0 to $20 \%$ infection relative to 'Fuchs', and susceptible where the degree of infection exceeded 20\% (Hsam et al., 1997). The segregation ratio of the $\mathrm{F}_{2}$ and $\mathrm{F}_{3}$ populations were analyzed using Chi-Square test for goodness of fit.

\section{DNA extraction}

Genomic DNA from all $F_{2}$ individuals was extracted from fresch 10day-old leaves using DNeasy Plant Mini Kit (Qiagen). DNA integrity and quality were evaluated by elektrophoresis on $1.5 \%$ agarose gel. DNA concentration was determined with NanoDrop2000 spectrophotometry

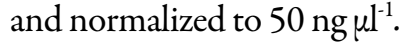

\section{High-troughput genotyping using the DArT-Seq ${ }^{T M}$ method}

A high-troughput genotyping method based on DArTseq technology was employed to genotype $F_{2}$ population. Restriction enzymes PstI and HpaII were selected for genomic complexity reduction. The silicoDArT markers were scored using DArTsoft as a binary data $(0 / 1)$, several quality parameters such as call rate, polymorphism information content (PIC) and reproducibility were calculated.

\section{Conversion of silicoDArT markers to PCR-based assay}

A SilicoDArT markers highly correlated with phenotype observations were chosen for further analysis.
Markers sequences associated with resistance to powdery mildew, were analyzed in CLC Main Workbench software version 7.8 to identify primer pairs for their amplification. The main criteria for primer design were as follows: primer size $16-22$ bp, $40-60 \%$ GC rich (optimum 50\%), minimum annealing temperature $55^{\circ} \mathrm{C}$ (optimum $60^{\circ} \mathrm{C}$ ), product size $>40 \mathrm{bp}$.

\section{Specific PCR}

Reaction mixtures in a final volume $10 \mu \mathrm{l}$, consisted 60 ng of total genomic DNA, 20-40 $\mu \mathrm{M}$ each of PCR primers (quantity was tested for each primers), $0.1 \mathrm{mM} \mathrm{dNTPs}$, 1.5$2.5 \mathrm{mM} \mathrm{MgCl}_{2}$ (quantity was tested for each primers), $1 \times$ reaction buffer and $0.5 \mathrm{U}$ Taq Polymerase ThermoFisher). PCR was conducted on T1BIometra thermalcycler. The following profile: $95^{\circ} \mathrm{C}-7 \mathrm{~min}, 35 \times 95^{\circ} \mathrm{C}-30 \mathrm{~s}, 56^{\circ} \mathrm{C}-30$ s, $72{ }^{\circ} \mathrm{C}-30 \mathrm{~s}$ with final elongation $72^{\circ} \mathrm{C}-5 \mathrm{~min}$ was used. The PCR products were separated on $2.5 \%$ agarose gels containing EtBr in TBE buffer at $140 \mathrm{~V}$ for $1 \mathrm{~h}$.

\section{Marker validation}

Converted silicoDArT-based markers were tested in all individuals of 'Av1860' × 'Fuchs' segregating population. Segregation evaluated based on silicoDarT and their converted counterparts were compared for congruency. Spearman rank correlation coefficients between converted markers and resistance of plant materials were calculated using Statistica softwere 13.1 (StatSoft, 2017). The significance of association between evaluated molecular profiles and resistant and susceptible plants was assessed via Pearson's Chi Square test (Bewick et al., 2004) using Statistica softwere 13.1 (StatSoft, 2017).

\section{Results}

\section{Analysis of resistance segregation}

'Av1860' $\times$ 'Fuchs' $F_{2}$ population were tested in 2 independent host-pathogen tests based on 2 different powdery mildew isolates. Segregation of the $F_{2}$ plants analyzed population deviated significantly from the ratio 3:1. Number of resistant and susceptible individuals was very similar for all used powdery mildew isolates: 124,119 resistant and 34, 39 susceptible plants were identified in test based on Kopaszewo 2015(1) pk and Czesławice 2015 (2) izolates respectively (Table 1).

The segregation for resistance to powdery mildew in $\mathrm{F}_{3}$ mapping population approximated a 1:2:1 ratio corroborating single-gene segregation (Table 1). Obtained results allow choosing resistant and susceptible homozygous form analyzed population.

To identify silicoDArT markers for $P m 4$ resistant gene to oat powdery mildew $F_{2}$ mapping population 'Av1860' $\times$ 'Fuchs' were analyzed using DArTseq methodology. A total of 46230 silicoDArT markers were identify in mapping population; 10564 markers were polymorphic among the 157 individuals of $\mathrm{F}_{2}$ population. The polymorphism information content (PIC) ranged from 0.013 to 0.500 with an average 0.374. 236 markers had a very low PIC (a value less than 0.05 ) which means that this markers characterized very low polymorphism. The call rate ranged from 79.2 to $100 \%$ with an average of $92.2 \%$ (Table 2). 
352

Among obtained silicoDArT markers 126 were high correlated with resistance to powdery mildew. Patterns of selected markers were very similar and allow distinguishing resistant and susceptible genotypes in mapping population. Segregation of all silicoDArT markers associated with Pm4 gene, across the population match to the ratio 3:1 (data not shown). Among these markers 48 sequences have been selected for potential conversion into specific markers, but only 20 were suitable for primer design. Two pairs of primers were designed for each sequence.

In first step all designed markers were tested on parental genotypes and bulks of resistant and susceptible individuals. 5 primer pairs amplified expected products in resistant bulks and 'Av1860' line. The rest of primer pairs produced amplicons in all tested genotypes.

Five primer pairs were tested on resistant and susceptible homozygous individuals from 'Av1860' $\times$ 'Fuchs' population. Only 3 primer pairs amplified expected patterns: product present in resistant and absent in susceptible genotypes (Table 3, Foto 1). These primers were verified on parental lines and 144 individuals of mapping population 'Av1860' $\times$ 'Fuchs'. Marker PM4-2 was observed in 112 among 146 analyzed genotypes. Expected amplification product was present in 103, among 108 resistant individuals and in 'Av1860' parental line and in 8 genotypes characterized as a susceptible in host-pathogen tests. This marker was highly correlated with resistance conditioned by $P m 4$ gene, correlation coefficient assumed value $r=0.759$ ( $p>0.0001)$. Second marker named Pm4-6 was observed in 112 analyzed genotypes. 102 individuals characterized as a resistant and 10 characterized as a susceptible possess this marker. Spearman rank correlation coefficients between marker and phenotype observation was also very high $(r=0.705, p>0.0001)$. Third successfully converted marker Pm4-9 was present in 99 individuals, 96 resistant and 3 susceptible genotypes possessed this marker. Correlation coefficient between this marker and phenotype observation assumed value $r=0.744(p>0.0001)$. The Chi square test indicated a significant association between individuals characterized as resistant and susceptible and converted molecular markers. The value of the $\chi^{2}$ test $(p=0.000)$ was 84.196 for Pm4-2 marker, 72.690 for Pm4-6 and 80.919 for Pm4-9.

Table 1. Seedlings response and segregation ratio of $F_{2}$ and $F_{3}$ families derived from 'Av1860' × 'Fuchs' cross inoculated with different Blumeria graminis DC. f.sp. avenae Em. Marchal isolates

\begin{tabular}{|c|c|c|c|c|c|c|c|c|c|}
\hline \multicolumn{5}{|c|}{$\mathrm{F}_{2}$ population ('Avl860' $\times$ 'Fuchs') } & \multicolumn{5}{|c|}{ F3 $_{3}$ population ('Avl860' × 'Fuchs') } \\
\hline Powdery mildew izolates & Resistant & Susceptible & Chi-square & P-value & Resistant & Segregating & Susceptible & Chi-square & P-value \\
\hline Kopaszewo 2015(1) pk & 123 & 35 & 0.544 & 0.30 & 57 & 72 & 35 & 4.902 & \\
\hline Czesławice 2015 (2) & 119 & 39 & 0.000 & 0.99 & 51 & 68 & 39 & 5.492 & 0.05 \\
\hline
\end{tabular}

Table 2. Quality parameters of the silicoDArT markers used to analyze 'Av1860' × 'Fuchs' mapping population

\begin{tabular}{cccc}
\hline Parameter & Maximum value & Minimum value & Average value \\
\hline Polymorphism information content & 0.500 & 0.013 & 0.374 \\
Reproducibility (\%) & 1.00 & 0.941 & 0.994 \\
Call rate (\%) & 100 & 79.2 & 92.2 \\
One ratio & 0.814 & 0.006 & 0.734 \\
\hline
\end{tabular}

Table 3. SilicoDArT markers successfully converted into SCAR

\begin{tabular}{ccccccc}
\hline $\begin{array}{c}\text { SilicoDArT } \\
\text { marker }\end{array}$ & SCAR primers & Primers sequence & $\begin{array}{c}\text { Primer } \\
\text { TM }\end{array}$ & $\begin{array}{c}\text { SCAR } \\
\text { length }\end{array}$ & $\begin{array}{c}\text { Segregation of converted } \\
\text { markers }\end{array}$ & $\begin{array}{c}\text { Correlation with } \\
\text { phenotype observation }\end{array}$ \\
\hline \multirow{2}{*}{10575906} & Pm4-2 F1 & CAGCCGTGAGGGTGAACT & 60 & 46 & $0.147(\mathrm{p}=0.50)$ & 0.759 \\
& Pm4-2R & GCTCTCCTTGTGAAGGTCCA & 60 & & & $0.147(\mathrm{p}=0.50)$ \\
\multirow{2}{*}{5420825} & Pm4-6F & GCCAAACCTGATAGTGACCAA & 60 & 47 & & 0.705 \\
& Pm4-6R & TACGCCAAGCGTGTCAGTTA & 60 & & & 0.744 \\
22075478 & Pm4-9F & GCAGGTGTGTCTGAATGTCG & 60 & 68 & $4.461(\mathrm{p}=0.02)$ & \\
& Pm4-9R & GGGCATCAGGCATATCG & 58 & & & \\
\hline
\end{tabular}

$\begin{array}{llll}A & B & \\ \text { resistant genotypes } & \text { susceptible genotypes } P P & \text { resistant genotypes susceptible genotypes }\end{array}$
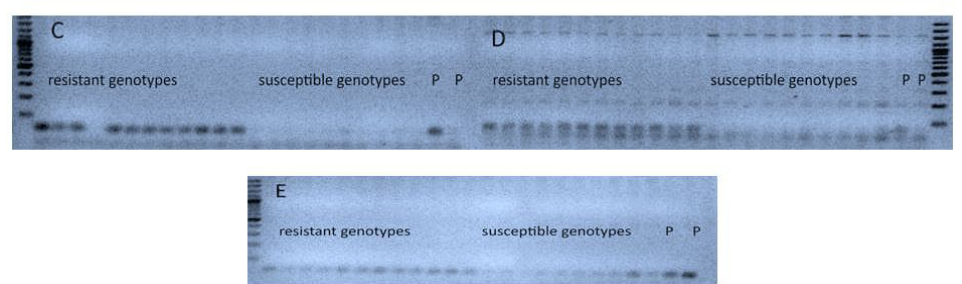

Fig. 1. Molecular profiles obtained with Pm4-2 (A), Pm4-3 (B), Pm4-6(C), Pm4-9 (D), Pm4-16 (E) primer pairs for resistant and susceptible individuals and parental line of 'Av1860' × 'Fuchs' population 


\section{Discussion}

One of the most important purpose of many plant breeding programs is to prevent decreases in yield due to fungal diseases. One of the most harmful oat fungal disease in powdery mildew caused by Blumeria graminis DC. f.sp. avenae Em. Marchal. Annual crop losses from mildew infections are estimated to range from $5-10 \%$ every year up to $40 \%$ in the years with high disease pressure (Lawes and Hayes, 1965; Jones, 1977; Roderick and Clifford, 1995). This is known that the most economical and environment friendly method for controlling fungal diseases is breeding cultivars with genetically conditioned resistance. In oat, identification of genotypes possessing some resistance to powdery mildew is based on the host-pathogen tests. These tests based on observation the effect of fungus infection on the studied form with unknown resistance and comparison this reaction with the effect appearing on lines with known resistant genes (Hsam et al., 1997; 1998; Kowalczyk et al., 2004; Yu and Herrmann, 2006; Okoń and Kowalczyk, 2012a; Okoń et al., 2016). It all makes it very time and work-consuming. Nowadays molecular markers are commonly used in breeding programmes as an easy and inexpensive method for selection interesting genotypes. Number of molecular markers used in marker assisted selection (MAS) in oat is very limited compared to other cereals like wheat or barley. It may be related to the fact that oats is low-input crop. However, there is a few examples of developing molecular markers for important oats traits like resistance to crown rust (Wight et al., 2003; Chong et al., 2004; McCartney et al., 2011), stem rust (Penner et al., 1993), long seed dormancy (Fennimore et al., 1999), dwarf genes (Milach et al., 1997), $\beta$-glucan content (Orr and Molnar, 2008) or powdery mildew (Yu and Herrmann, 2006; Okoń and Kowalczyk, 2012a). Yu and Herrmann (2006) developed two molecular markers linked to Pm5 resistant gene to powdery mildew on common oat, but this gene is not popular in breeding programmes. Okoń and Kowalczyk (2012b) identified molecular marker linked to Pm6 (OMR2 group) resistant gene, unfortunately this gene is not effective against existed powdery mildew races (Okoń, 2015). In this study, an attempt was made to develop a SCAR marker for Pm4 resistant gene to powdery mildew in oat. Pm4 is nowadays the most effective source of resistance against powdery mildew and could be used in breeding programmes to increase the level of resistance of cultivated oat (Okoń, 2015). To developed marker specific to Pm4 DArTseq methodology was used.

The DArTseq technology results in two sets of markers: dominant and more numerous silico-DArT, and codominant and more informative SNP. This highthroughput genotyping method have been used for extending the dense of genetic map (Ren et al., 2015; Milczarski et al., 2016), evolutionary relationships (AlBeyroutiová et al., 2016), genomic selection (dos Santos et al., 2016) In our study silico-DArT markes were used for identification of molecular markers associated with Pm4 resistant gene in oat. Number of markers associated with analysed gene was very high. 126 markers showed similar pattern and segregated according to phenotypic observations.
Because of the short sequence of silico-DArT markers, their conversion in a simple PCR method is a very difficult challenge. In available literature there is limited information about successful conversion of silico-DArT markers. Milczarski et al. (2016) have found DArTseq markers associated with $R f c l$ gene in rye. Unfortunately the attempt to convert these markers failed. But authors mentioned that sequence data obtained during DArTseq analysis sometimes allow for designation of primers revealing polymorphism within mapping population, but the frequency of such cases is low.

In our study we design primer for 20 potential silicoDArT markers highly associated with Pm4 gene, among these markers only 5 produce expected patterns in parental line and bulks of resistant and susceptible genotypes. Finally only 3 primer pairs produce expected patterns across the mapping population. It showed that conversion of silicoDArT markers into simple method based on PCR is possible, but efficiency of this process is very low. The available literature indicates that converted DArT-based markers usually maintain the segregation pattern of original DArTs (Ekstein et al., 2014; Shashin et al., 2009). Our investigation showed that a similar situation occurs when we try to convert DArTseq markers. In our study all SCAR markers reveal segregation patterns very similar to the original silicoDArT markers, which confirm correct conversion. Analysis of the correlation of converted silicoDArT markers with the resistance to powdery mildew conditioned by Pm4 gene demonstrated that they can be useful for selection purposes. It is very important to note that obtained molecular markers are dominant. Thus, additional experiments will be required to design codominant marker which will be allow to confirm homozygosity of the genotypes form 'Av1860' × 'Fuchs' population.

\section{Conclusions}

Conducted study is the first to develop effective molecular markers for the Pm4 powdery mildew resistance gene in oat. They confirm the possibility of converting DArTseq markers into PCR-specific markers, which can be used in marker assisted selection (MAS).

\section{Acknowledgements}

This work was supported by the Ministry of Agriculture and Rural Development in the frame of basic research program for biological progress in crop production, project number 91, under the title: "Identification and localization of DNA markers for selected powdery mildew resistance genes in common oat and pyramiding of the effective resistance genes in the oat genome".

\section{References}

Al-Beyroutiová M, Sabo M, Sleziak P, Dušinský R, Birčák E, Hauptvogel P, Kilian A, Švec M (2016). Evolutionary relationships in the genus Secale revealed by DArTseq DNA polymorphism. Plant Systematics and Evolution 302:1083-1091. 
354

Aung T, Thomas H (1978). The structure of breeding behaviour of a translocation involving the transfer of mildew resistance from Avena barbata Pott. into the cultivated oat. Euphytica 27:731-739.

Aung T, Thomas H, Jones T (1977). The transfer of the gene for mildew resistance from Avena barbata ( $4 x)$ into the cultivated oat $A$. sativa by an induced translocation. Euphytica 26:623-632.

Bayles RA (1997). Disease development - the interaction of variety resistance and pathogen. Aspects of Applied Biology 50:249-254.

Bennett FGA (1984). Resistance to powdery mildew in wheat: a review of its use in agriculture and breeding programmes. Plant Pathology 33:279300.

Bewick V, Cheek L, Ball J (2004). Statistics review 8: qualitative data - tests of association. Critical Care 8:46-53.

Chhetri M, Bariana H, Wong D, Sohail Y, Hayden M, Bansal U (2017). Development of robust molecular markers for marker-assisted selection of leaf rust resistance gene $L r 23$ in common and durum wheat breeding programs. Molecular Breeding 37(3):21.

Chong J, Reimer E, Somers D, Aung T, Penner GA (2004). Development of sequence-characterized amplified region (SCAR) markers for resistance gene $P c 94$ to crown rust in oat. Canadian Journal of Plant Pathology 26:89-96.

Clifford BC (1995). Diseases, pest and disorders of oat. In: Welch RW (Ed). The Oat Crop. Chapman \& Hall,London pp 252-278.

Collard BCY, Jahufer MZZ, Brouwer JB. Pang ECK (2005). An introduction to markers, quantitative trait loci (QTL) mapping and marker-assisted selection for crop improvement: the basic concepts. Euphytica 142:169-196.

Collard BCY, Mackill DJ (2008). Marker-assisted selection: an approach for precision plant breeding in the twenty-first century. Philosophical Transactions of the Royal Society of London. Series B Biological Sciences 363:557-572.

dos Santos JPR, Pires LPM, de Castro Vasconcellos RC, Pereira GS, Von Pinho RG, Balestre M (2016). Genomic selection to resistance to Stenocarpella maydis in maize lines using DArTseq markers. BMC Genetics 17-86.

Ekstein P, Rossnagel B, Scoles G (2008). DArTs without the DArT board: the application of individual DArT markers to marker-assisted selection. The 8th International Oat Conference, June 28th-July 2nd, 2008, Minneapolis, MN. Session VI - Plant Breeding, Germplasm Utilization and Cereal Genomics - Poster VI-9. https://wheat.pw.usda.gov/GG2/ Avena/event/IOC2008/IOCposter/VI-9_Eckstein.pdf.

FennimoreSA, Nyquist WE, Shaner GE, Doerge RW, Foley ME (1999). A genetic model and molecular markers for wild oat (Avena fatua L.) seed dormancy. Theoretical and Applied Genetics 99:711-718.

Hsam SLK, Pederina E, Gorde S, Zeller FJ (1998). Genetic studies of powdery mildew resistance in cultivated oat (Avena sativa L.). II. Cultivars and breeding lines grown in Northern and Eastern Europe. Hereditas 129:227-230.

Hsam SLK, Peters N, Paderina EV, Felsenstein F, Oppitz K, Zeller FJ (1997). Genetic studies of powdery mildew resistance in common oat (Avena sativa L.). I. Cultivars and breeding lines grown in Western Europe and North America. Euphytica 96:421-427.
Jones IT (1977). The effect on grain yield of adult plant resistance to mildew in oats. Annals of Applied Biology 86:267-277.

Jones IT, Jones ERL (1979). Mildew of oats. UK Cereal Pathogen Virulence Survey 1978. Annual Reports pp 59-63.

Kowalczyk K, Hsam SLK, Zeller FJ (2004). Identification of oat powdery mildew resistance group 2 (OMR2) and Polish common oat (Avena sativa L.) cultivars. Workshop "Resistance of cereals to biotic stresses", Radzików, Poland 28.11-01.12.2004:122-125.

Lawes DA, Hayes JD (1965). The effect of mildew (Erysiphe graminis f.sp. avenae) on springoats. Plant Pathology 14:125-128.

McCartney CA, Stonehouse RG, Rossnagel BG, Eckstein PE, Scoles GJ, Zatorski T, Beattie AD, ChongJ (2011). Mapping of the oat crown rust resistance gene Pc91. Theoretical and Applied Genetics 122:317-325.

Milach SCK, Rines HW, Philips RL (1997). Molecular genetic mapping of dwarfinggenes in oat. Theoretical and Applied Genetics 95:783-790.

Milczarski P, Hanek M, Tyrka M, Stojałowski S (2016). The application of GBS markers for extending the dense genetic map of rye (Secale cereale L.) and localization of the $R f c 1$ gene restoring male fertility in plants with the C source of sterility-inducing cytoplasm. Journal of Applied Genetics 57:439-451.

Okoń S (2012). Identification of powdery mildew resistance genes in Polish common oat (Avena sativa L.) cultivars using host-pathogen tests. Acta Agrobotanica 65(3):63-68.

Okoń $S$ (2015). Effectiveness of resistant genes to powdery mildew in oat. Crop Protection 74:48-50.

Okoń S, Kowalczyk K (2012a). Deriving isolates of powdery mildew in common oat and using them to identify selected genes of resistance. Acta Agrobotanica 65(2):155-160.

Okoń S, Kowalczyk K (2012b). Identification of SCAR markers linked to resistance to powdery mildew on common oats (Avena sativa L.). Journal of PlantDisease and Protection 119(5/6):179-181.

Okoń S, Ociepa T, Paczos-Grzęda E, Kowalczyk K (2016). Analysis of the level of resistance Polish oat varieties (Avena sativa L.) to powdery mildew (Blumeria graminis DC. F. sp. avenae Em. Marchal.). Annales UMCS71(3):51-60.

Orr W, Molnar SJ (2008). Development of PCR-based SCAR and CAPS markers linked to $\beta$-glucan and protein content QTL regions in oat. Genome 51:421-425.

Penner GA, Chong J, Levesque-Lemay M, Molnar SJ, Fedak G (1993). Identification of RAPD marker linked to the oat stem rust gene Pg3. Theoretical and Applied Genetics 85:702-705.

Rajhaty T (1963). A standard karyotype for Avena sativa. Canadian Journal of Genetics and Cytology 5:127-132.

Ren R, Ray R, Li P, Xu J, Zhang M, Liu G, Yao X, Kilian A, Yanget X (2015). Construction of a high-density DArTseq SNP-based genetic map and identification of genomic regions with segregation distortion in a genetic population derived from a cross between feral and cultivatedtype watermelon. Molecular Genetics and Genomics 290:1457-1470.

Roderick HW, Clifford BC (1995). Variation in adult plant resistance to powdery mildew in spring oats under field and laboratory conditions. Plant Pathology 44:366-373. 
Roderick HW, Jones ERL, Šebesta J (2000). Resistance to oat powdery mildew in Britain and Europe: a review. Annals of Applied Biology 136:85-91.

Schwarzbach E, Smith IM (1988). Erysiphe graminis DC. In: Smith IM et al.(Eds). European Handbook of Plant Diseases. Blackwell, Oxford.

Sebesta J, Kummer M, Roderick HW, Hoppe HD, Cervenka J, Swierczewski A, Muller K (1991). Breeding oats for resistance to rusts and powdery mildew in central Europe. Ochrana Rostlin 27:229-238.

Sebesta J, Roderick HW, Jones TI, Jones ERL, Herrmenn M, Zwatz B, Corazza L (1997). The occurrence of oat powdery mildew in Europe and effectiveness of sources of resistance. Petria 7:121-140.

Shahin A, Arens P, Heusden S, van Tuyl JM (2009). Conversion of molecular markers linked to Fusarium and virus resistance in Asiatic lity hybrids. Acta Horticulturae 836:131-136.
StatSoft Inc. (2017). STATISTICA (data analysis software system), version 13.1. www.statsoft.com.

Wight CP, O’Donoughue LS, Chong J, Tinker NA, Molnar SJ (2005). Discovery, localization and sequence characterization of molecular markers for the crown rust resistance genes Pc38, Pc39 and Pc48 in cultivated oat (Avenasativa L.). Molecular Breeding4:349-361.

Wight CP, Tinker NA, Kianian SF, Sorrells ME, O’Donoughue LS, Hoffman D, ... Molnar SJ (2003). A molecular marker map in 'Kanota' $\times$ 'Ogle' hexaploid oat (Avena ssp.) enhanced by additional markers and a robust framework. Genome 46:28-47.

Yu J, Herrmann M (2006). Inheritance and mapping of a powdery mildew resistance gene introgressed from Avena macrostachya in cultivated oat. Theoretical and Applied Genetics 113:429-437. 